\title{
Experimental Teaching Design of the Credit Risk Analysis Based on Situational Method*
}

\author{
Yin Yu \\ The College of Economics and Management, Shanghai Second Polytechnic University, Shanghai, China \\ yuyin@sspu.edu.cn
}

\begin{abstract}
The credit risk analysis is important in finance and credit management and has the characteristics of profound theories and lots of model, so that it is difficult in understanding to students. By using Situational Method and the powerful data analysis functions of Excel, the abstracted theoretical knowledge and models can be played visually to attract the students to be interested in. The teaching process and methods were discussed in mining and expanding the width and depth of the teaching contents by Excel and Situational Method for training the ability of the students to ask, analyzing and dealing with questions.

Index Terms - Situational Method, Credit risk analysis, Credit management, Excel
\end{abstract}

\section{Introduction}

The credit risk analysis is important in the finance or the credit management, and has the characteristics of profound theories and lots of models. There were two models in teaching of credit risk analysis, emphasizing sizing on the qualitative description of credit risk analysis theories and the mathematical derivation of analysis models respectively. Specifically, the former seems to be easy for most students but lacks quantitative contents and goes against students' application in future, while the latter requires students to have good mathematical foundation or else to have great difficulties in understanding. Moreover, two modes have a common disadvantage: theory and application fail to be combined well.

With the aim of improving practicality of credit risk analysis, the methods of reducing modelling processes and increasing model applications are selected, and the Situational Method based on Excel is used for reference to innovate in the experimental teaching contents. In this paper, taking design of a serial experimental teaching case as an example, Excel is used to weaken modelling process and strengthen model application, and the Situational Method is combined to broaden and exploit teaching contents, for the purpose of helping students to arouse learning interest and cultivating their ability to deal with problems.

\section{Application of Situational Method}

\section{A. Situational Method}

Li Jilin[1], a famous educator of elementary and secondary school in China, created the "Situational Teaching", "Situational Education" and "Situational Curriculum" and established the theoretical framework and operating system of situational education, which became an important model of quality-oriented education in China. The Situational Method is a teaching method which introduces or creates purposefully the vivid and emotional scenes and images in the course of teaching to arouse students' attitude and experience, help them to understand teaching material and develop their psychological functions. Based on such theories as the interaction between emotion and cognition, intuitiveness of cognition, similarity of noetic science, psychic unity of consciousness and unconsciousness, and unity of intelligence and non-intelligence factors, the Situational Method, whose core lies in motivating students' emotion, emphasizes a teaching process of "putting forward teaching tasks with a view to development, optimizing the teaching pro- gram and then creating scenes according to teaching tasks, student characteristics and teacher's quality".

In general, the scenes as mentioned above can be created by means of life presentation, real object demonstration, pictorial representation, music playing, performance experience and language description, for the purpose of enlightening students and improving their creative thinking. The Situational Method, in particular, has been widely applied in teaching of elementary and secondary schools in China and achieved good teaching effects.

As a second-tier school, the University belongs to the undergraduate school of level 4 in Shanghai. With the aim of characteristic development, the school is positioned in the career-oriented higher education and lays stress on cultivation of professional abilities. How to represent the above aim in teaching is also a problem worth consideration. On this account, how to apply the Situational Method to teaching of credit risk analysis with the characteristics of profound theories and lots of models and to create scenes which are suitable to students' age and knowledge structure is one of key problems to be considered by the author. The characteristic that scene creation by means of language description is more appropriate for older groups provides favourable conditions for application of the Situational Method to teaching of credit risk analysis.

\section{B. Problems and Solutions}

Teaching feedback shows that most students think there are considerable gaps be- tween their foundation of mathematics and mathematical knowledge required for credit risk analysis;

\footnotetext{
* This work is partially supported by the Key Course Construction Project and the Discipline Construction Project (No. XXKPY1313) of Shanghai Second Polytechnic University.
} 
moreover, teaching time, only 48 class hours, is inadequate and the contents are abstract, so it is very difficult in understanding those contents. In particular, students are hard to combine those contents with application and thus get no interest in learning. In order to solve the problems mentioned above, the Situational Method is used. Specifically, abstract contents are presented by means of model deduction based on software as well as rich and intuitive schematic analysis, which will be helpful for the understanding of students [2].

Teaching of experimental lessons has been strengthened for students of the credit management since Entry Year 2010. 48 class hours, in total, are divided into 30 hours for teaching of theoretical lessons and 18 hours for teaching of experimental lessons. As most of students are poor at programming and also have no interest in it, the powerful userfriendly software needs to be considered [3] [4]. As the powerful software for spreadsheet data analysis and processing, Excel has rich graphing functions and seems to be learned more easily than other professional soft- ware due to less dependence upon mathematics and statistics, and its many functions have no need of programming, so it meets requirements of teaching and learning. As a result, Excel becomes an ideal option.

\section{Experimental Design}

\section{A. Experiments}

A serial experimental teaching case is de- signed according to the above condition and consists of five cases which go from the easy to the difficult, in order to make students better understand those contents in a progressive manner.

Experiment 1: There are 10 bonds in a credit default swap basket. The probability of default for each of the bonds is $5 \%$. The probability of any one bond defaulting is completely independent of what happens to the other bonds in the basket. What is the probability that exactly one bond de-faults? [5]

As seen in above question, it meets all conditions of $\mathrm{N}$ fold independent experiments and follows the binomial distribution, which requires students are familiar with binomial expansion. Students have learnt the probability theory and mathematical statistics and must be capable of applying their knowledge to specialized courses.

Experiment 2, shown in the following, can be derived from Experiment 1:

Experiment 2: A package credit de- fault swap includes 10 bonds, and default probability of each bond is 5\%. Default of bonds is independent of each other. What's the probability for at least one bond defaulted?

For this question, students understand easily that "at least one bond defaulted" is the sum of "no bond defaulted" and "only one bond defaulted". Obviously, the cu- cumulative probability is calculated.

After students understand both difference and relation between probability density and cumulative probability, experiment 3 is designed as follows:
Experiment 3: A package credit de- fault swap includes $\mathrm{N}$ bonds, and default probability of each bond is $\mathrm{p}$. Default of bonds is independent of each other. What's the probability for only $\mathrm{n}$ bond(s) defaulted? What's the probability for at least $\mathrm{n}$ bond(s) defaulted? $\mathrm{n}=0,1,2 \ldots, \mathrm{N}$.

Most students easily know that Case 3 is the combination of Case 1 and Case 2, with large amounts of calculation. They request reduction in amounts of calculation, which, consequently, lays the foundation for application of Excel.

Based on the Situational Method and demonstration in classroom, the following question is designed by means of language description:

Experiment 4: You are a credit man- ager or bank credit analyst and prepare to operate a package credit swap which includes several bonds. As a practitioner adept in risk diversification, you want to know in advance its risk profile. Your initial analysis reveals that default of those bonds is independent of each other and default probability of each bond is $5 \%$. Now, you intend to know default risk of this credit swap, and how would you calculate it?

When dealing with this problem, students raise the following questions: How to set number range of spin button for total number of bonds? Can it be set arbitrarily? By now, the question shown in the following can be raised:

Experiment 5: If you design a package credit default swap, how many bonds included is appropriate? What happens in case of fewer bonds or more bonds?

The progressive five cases extend from initial calculation to design of credit default swap and to thinking about risk management and control. Excel not only shows the default status when total number of bonds and number of defaulted bonds change but also make comparison easily, so students are easy to put forward their opinions and capable of verifying or modifying them in future learning of professional knowledge.

\section{B. Application of Excel}

Application of Excel is divided into two parts: demonstration and experimental exercise by students themselves.

Demonstration. Experiment 1-3, as the designed demonstration contents, are solved by Excel with three functions, i.e. "Call Function of Excel", "Spin Button" and "Data Validation". Application level of Excel functions reflects directly the mathematical foundation of students.

Experimental Exercise. In the first place, students represent by themselves the contents which were demonstrated in classroom. Since they rarely used this soft- ware and weren't trained and most of them just regarded it as calculator, how to trans- form a problem into the form which can be solved by Excel needs to be enlightened.

\section{Conclusions}

Data processing of Excel is able to show intuitively the abstract theories and models, and the Situational Method is combined to broaden and exploit teaching contents. In practice, arrangement of students for exercise by themselves can often achieve good effects, which can not only motivate learning 
interest but also cultivate their abilities to think about, raise, analyze and deal with problems. After application of Excel and exercise by themselves, there are three transformations in specific problems: from simple "listening" to participation in teaching process; from solving manually the purely theoretical problems and virtual data analysis problems to analysis of actual economic and financial data; from misunderstanding to raising simple questions. Moreover, students have a strong interest in Excel feature.

We make further efforts to study how to apply Excel and the Situational Method to teaching and learning of credit risk analysis in a better and more effective way for weakening modelling process and strengthening model application, so that courses are oriented towards the school's goal of cultivating the professional and top-class applied talents.

\section{References}

[1] Li Ji-lin, Operation and Cases of Situational Curriculum, Educational Science Publishing House, Beijing, 2008

[2] Li Jin-dong, Application of EXCEL in Teaching of Portfolio Theories, Journal of Harbin Finance University, pp.96-2011, 12(6).

[3] Zhang Su-lin, Modern Portfolio Teaching Methods - Excel-Based Realization. Journal of Chongqing University of Technology (Social Science), pp.123-1252010, 3(24).

[4] Zhao Wei-xu, Application of Excel in Teaching of Finance in Colleges and Universities, China Management informationization, pp. 117-118, 2010, 15(13).

[5] Jorion, P., Financial Risk Manager Handbook, sixth Edition, John Wiley \& Sons, Inc., 2011. 